\title{
Modelling a pit lake district to plan for abstraction regime changes
}

\author{
C.D. McCullough Mine Water and Environment Research Centre (MiWER), Australia
}

M. Müller Hydrocomputing UG (haftungsbeschränkt) \& Co. KG, Germany

K. Eulitz Ingenieurbüro für Grundwasser GmbH, Germany

M.A. Lund Mine Water and Environment Research Centre (MiWER), Australia

\begin{abstract}
Mining pit lakes can form in open cut mining pits that extend below the groundwater table. Final lake surface levels generally represent the greatest risk of pit lake closure to stakeholders through potential to overflow and discharge to regional surface water bodies and groundwater resources. An essential prerequisite for managing this risk is a good understanding of the lake's water budget.

Pit lakes in the Collie Coal Basin, Western Australia form a lake district currently consisting of 13 lakes exceeding a total volume of $200 \mathrm{GL}$ of acid and metalliferous (AMD) degraded water. Given long-term risks for off-site contamination, regulatory agencies often rely on geochemical predictions of future pit lake water quality to evaluate closure strategies that protect the surrounding environment.

Using an existing regional groundwater model, we modelled representative pit lake types in the Collie Lake District, south-western Australia, to determine different regional groundwater abstraction regime effects on pit lake water levels. PITLAKQ was used to model three different lakes representing three distinct lake types identified by conceptual modelling: Historic (around 50 years old), New/Rehabilitated, and New/ Un-rehabilitated (both around 5-15 years old). An accurate representation of the water level-volume relationships was developed before all available data on major hydrological sinks and sources such as groundwater inflow/outflow, surface water inflow/outflow, as well as precipitation and evaporation were considered in lake water budget calculations.
\end{abstract}

Although we found large deviations between measured and calculated water levels we could show reasonable limits for groundwater inflows and outflows by examining different scenarios. Reciprocally, this improved the groundwater model(s) suggesting coupling fine-scale pit lake models with groundwater models to identify the data quality for sinks and sources as an approach for other pit lake models.

Our modelling scenarios showed that planned groundwater abstraction regime changes would lead to only limited changes in lake water depth compared to modelling uncertainties resulting from limited available data and the use of a regional groundwater model. This example illustrates pit lake modelling with low data availability still allows useful scenario testing under different operational scenarios.

\section{Introduction}

The size of mining pit lakes in Australia ranges from relatively small urban borrow pits of about $100 \mathrm{~m}$ in diameter, to enormous open cut operations such as Mount Whaleback Mine in the Central Pilbara, (WA) with final pit dimensions of $5.5 \mathrm{~km}$ by $2.2 \mathrm{~km}$ and a depth of $500 \mathrm{~m}$ (Waterhouse and Davidge, 1999). It is not known how many pit lakes exist in Australia, although, it has been estimated that there are more than 1,800 mine pits in Western Australia that could potentially form pit lakes (Johnson and Wright, 2003). These new mining pit lakes have few natural counterparts in Australia, especially in depth (Kumar et al., 2009). The mining areas also occur across a broad range of climatic regions, however, approximately one-third of Australia is arid with rainfall less than $250 \mathrm{~mm}$ per year and another one third is semi-arid $(250-500 \mathrm{~mm}$ per year). There are few areas where rainfall exceeds evaporation on an annual basis (Bell, 2001), however, the Collie region has been identified as an area where pit water quality is unlikely to undergo significant salinisation through evapo-concentration (Kumar et al., 2009). If pit lake water levels are sustainable under increased groundwater abstraction in this region then beneficial end use opportunities are more available (McCullough et al., 2009). 
As one of the driest continents in the world and with the demand for water resources by industry and an increasing population, pit lakes may be of significant potential use for both industry and surrounding communities (McCullough and Lund, 2006). Given the long-term risks for over-flow, mining companies and regulatory agencies rely on geohydrological predictions of future pit lake water levels, aiming to develop closure strategies that can provide sustainable protection of the surrounding environment and groundwater resources.

\subsection{Pit lake modelling}

There are several modelling strategies for mine lakes, hydrological modelling focusing on the input and discharge of ground and surface waters (Niccoli, 2009); physical limnology modelling for pit lake stratification and circulation (Hamblin et al., 1999; Castendyk and Webster-Brown, 2007); geochemical modelling on pit lake geochemistry and water quality (Eary, 1999); and biological modelling on ecological community structure (Kalin et al., 2001; Jin and Bethke, 2005). Nevertheless, a considerable amount of both pit lake and often relevant catchment data is also needed to produce accurate results for modelling prediction in these disciplines.

There are many physical processes which control pit lake hydrodynamics. These include the shape, orientation of the lake, and climatic conditions at the site (Miller et al., 1996; Huber et al., 2008). Incoming solar and outgoing evaporation and radiation contributes to a heat balance which controls lake water temperature and therefore water density in freshwater systems, affect mixing and stratification, as will wind stress across the pit lake surface, transferring energy to depth. In turn, the hydrological pit lake balance is determined by lake depth and volume and relative inputs of water (e.g. precipitation, surface water and ground water influx) and water removal (e.g. evaporation, surface and ground water efflux, and abstraction) (Salmon et al., 2008). Therefore, modelling pit lake water levels requires hydro-geological, limnological, and climatic processes all to be considered.

Despite potential and existing examples of possible beneficial end uses for pit lakes, there are many pit lakes across the Australian continent with no planned end uses (Farrell, 1998). The potential use of pit lake water remains largely dependent on the pit lake water quantity and quality (Doupé and Lymbery, 2005). However, a frequent lack of detailed data of pit lake water quantity and quality currently renders it impossible to assess the risk and opportunities presented by pit lakes. Current predictive pit lake models are able to provide information for advancing current conceptual models and provide advice of pit lake response to different management scenarios (McCullough et al., 2009). Although there are often no guidelines for developing pit lakes as useful water resources, pit lakes with good water quality can be used immediately for uses such as aquaculture, water sports and recreation, etc.

\subsection{Study site}

Located in the south-west of Western Australia, Collie is surrounded by the Collie Coal Basin which is the centre of coal mining industry in Western Australia (Figure Figure 1). Underground and open cut coal mining has taken place in the Collie basin since 1898. Until the mid 1990s, coal mining was predominantly found in the Cardiff sub-basin. In 1997, mining in the Cardiff sub-basin ceased and since then mining has taken place in the Premier sub-basin at the Muja, Ewington and Premier Mines.

Collie has a Mediterranean climate, with hot, dry summers (range $12-29^{\circ} \mathrm{C}$ ) and cool, wet winters (range $4-15^{\circ} \mathrm{C}$ ). The 100 year mean annual rainfall for the Collie Basin is $939 \mathrm{~mm}$, although this has decreased to an average of only $690 \mathrm{~mm}$ over the past 20 years (Craven, 2003). The hydrogeology of the Collie basin is complex, with multiple aquifers as a result of aquicludes and faulting (Varma, 2002). Groundwater resources of the Collie basin are fresh and discharge towards the Collie River, with seasonal fluctuations up to $1 \mathrm{~m}$ (Sappal et al., 2000). The $\mathrm{pH}$ of groundwater is highly variable ranging from <4 to neutral (Varma, 2002). There are currently more than 13 mine lakes in Collie, with surface area between 1-10 ha, depth between 10-70 m, age between 1-50 years and $\mathrm{pH}$ between 2.4-6.8 (Lund and McCullough, 2008). Water quality of pit lakes of Collie is degraded by acidic and metalliferous drainage (AMD) causing low $\mathrm{pH}$ and elevated concentrations of selected metals due to low buffering capacity of surrounding geologies. 


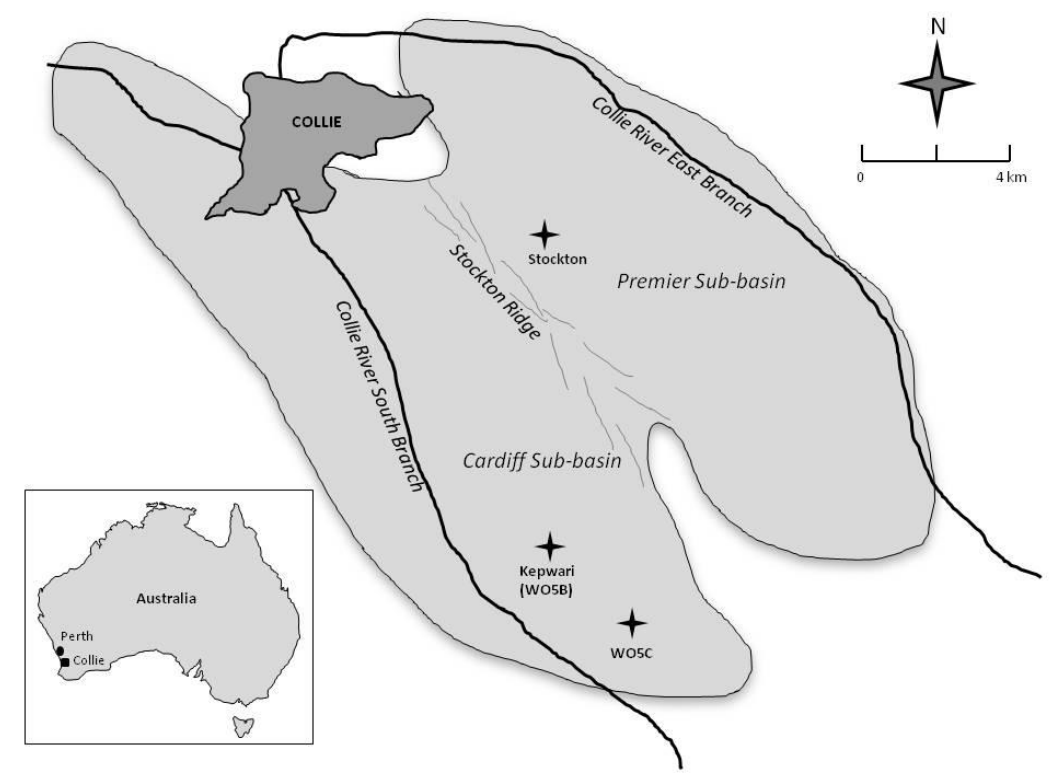

Figure 1 Location of the Collie Lake District and representative study pit lakes

\section{Methods}

\subsection{Modelling software}

The PITLAKQ (Müller, 2011) numerical modelling software is based on MODGLUE (Müller, 2004), which had been applied to several lakes (Müller and Werner, 2004; Werner et al., 2008). PITLAKQ accounts for the determining physical, chemical, and biological processes of acidic mining pit lakes. Figure 2(a) a gives a schematic overview of important processes in acidic pit lakes that are implemented in the model. The principle of spatial discretisation is shown in Figure 2(b).

(a)

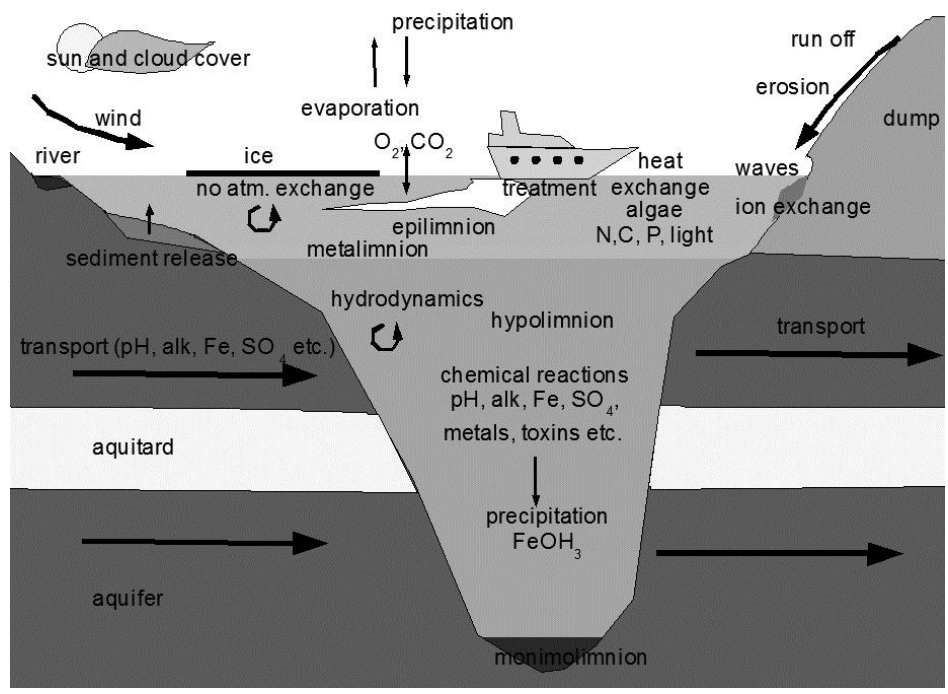

(b)

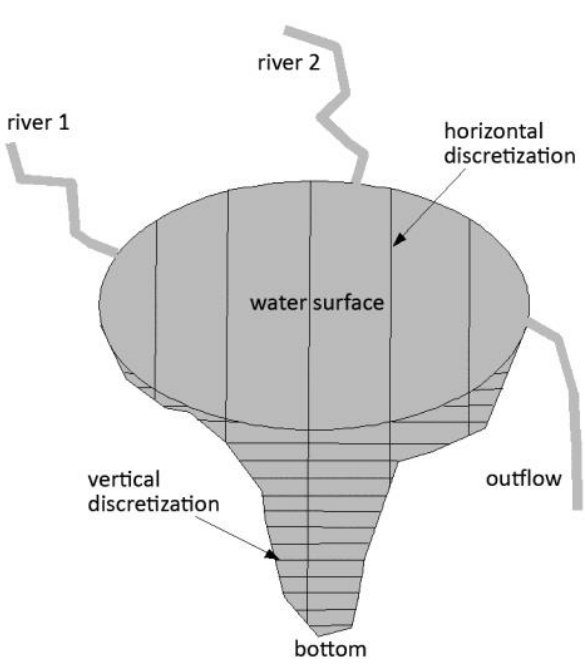

Figure 2 a) Schematic of processes in PITLAKQ; b) Principle of spatial discretisation

PITLAKQ couples CE-QUAL-W2 (Cole and Buchak, 1995) and PHREEQC (Parkhurst and Appelo, 1999) and adds new functionality to account for the pit lake requirements. For example, several sources of acidity such as erosion or release from submerged sediments and spatially distributed groundwater inflow help to better represent pit lake conditions. Furthermore, PITLAKQ can account for the effects of water treatment on water quality. The two-dimensional model setup with one vertical and one horizontal dimension allows sinks and sources with defined spatial locations. 


\subsection{Lake types}

Previous conceptual modelling of Collie Lake District pit lakes identified three major lake types (McCullough and Lund, 2010). These lake types all showed similar water quality and environmental characteristics and therefore are expected to show similar developmental behaviour. The three basic lakes types included: Historic pit lakes (around 50 years old), New and Rehabilitated pit lakes (around 5-15 years old) and New and Un-rehabilitated pit lakes (around 5-10 years old, but with revegetation <5 years old). Differences between pit lakes were predominantly due to higher $\mathrm{pH}$ and lower ORP in historic pit lakes, high salinity in rehabilitated pit lakes and lower salinity and $\mathrm{pH}$ in un-rehabilitated pit lakes. Modelling was made for a single example of each of the three lake types previously identified by conceptual modelling shown in Table 1. These lakes were each chosen as representatives of their respective lake types and also for having a good dataset to best enable modelling accuracy. Hourly air temperature, dew point temperature, wind speed, wind, direction, precipitation, and cloud cover data (from precipitation data) from the Collie East weather station was used to characterise lake upper boundaries.

Table 1 Pit lake types modelled and their bathymetry
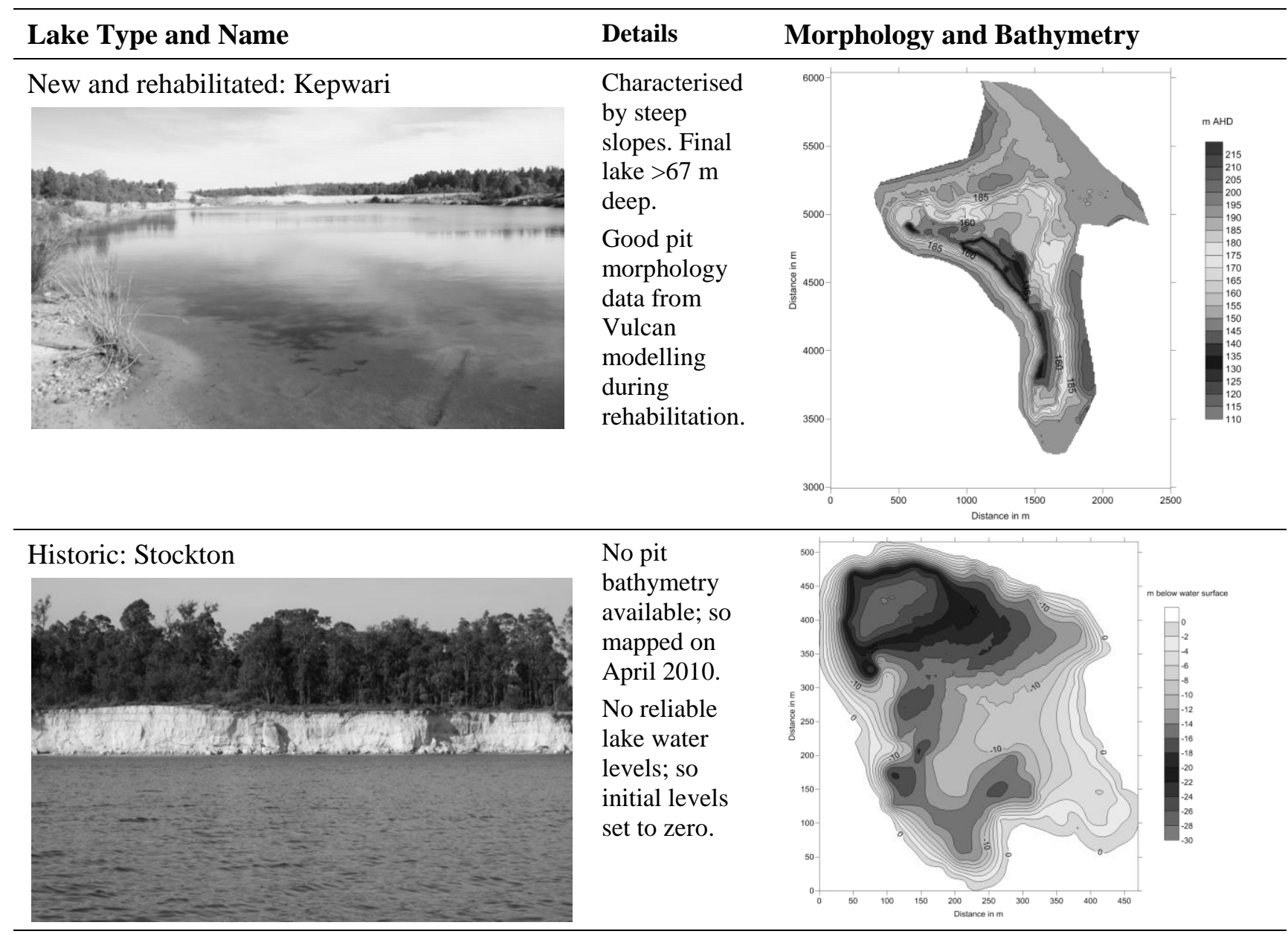

No pit bathymetry available; so mapped on April 2010.

No reliable lake water levels; so initial levels set to zero.
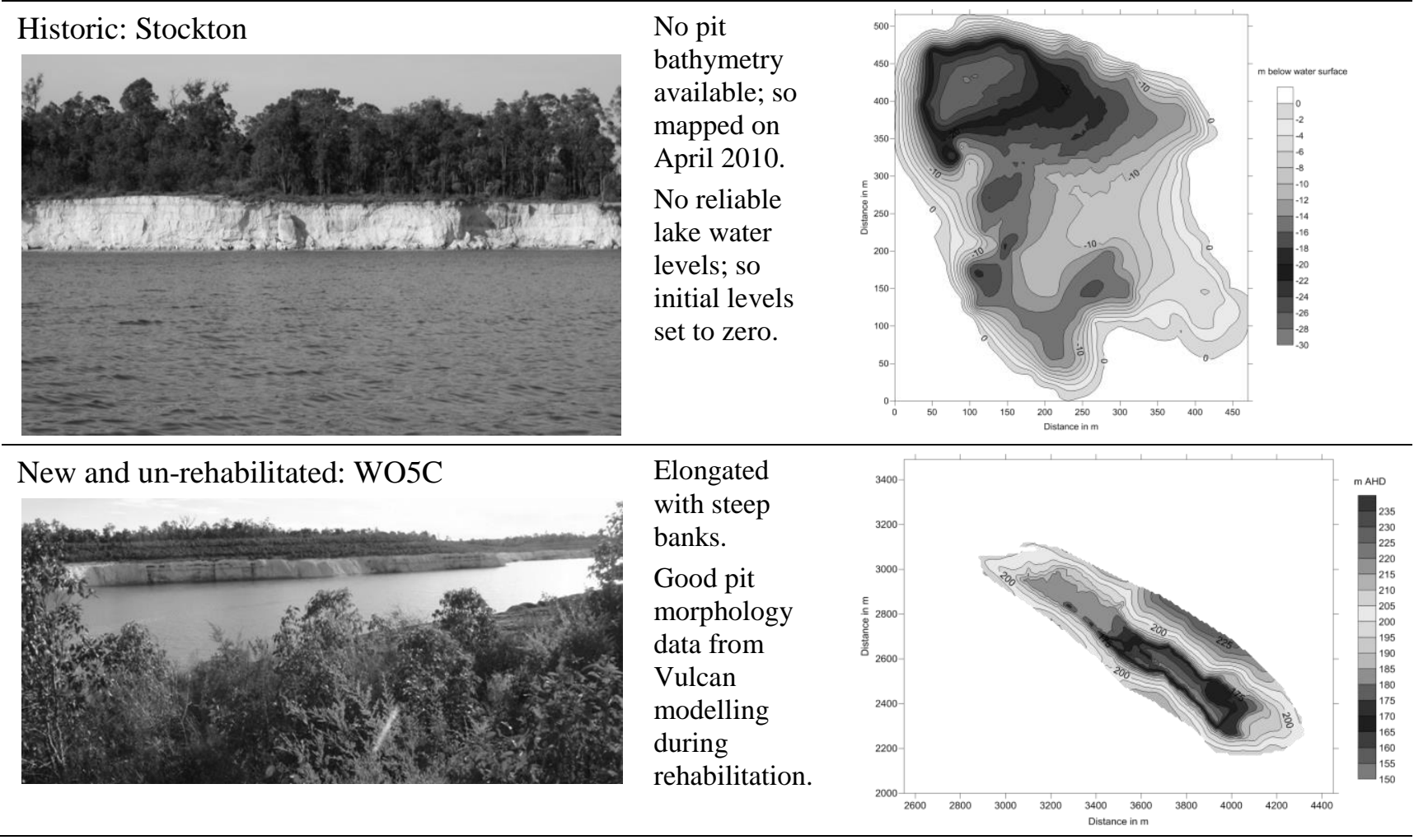
Varma (2002) considered groundwater a very important source of water and acidity influx for the Collie lakes where pyrite containing backfill may often constitute the immediate pit catchment and walls. A numerical MODFLOW-based groundwater model for the Collie Basin was built by Zhang et al. (2007). Recently, a FEFLOW-based groundwater flow model has also been developed. This FELOW-based model was a successor of the MODFLOW-based model using much of the same input data but at the same time taking advantage of the greater flexibility of the Finite Element Modelling (FEM) mesh of FEFLOW. This yielded a better spatial representation of smaller features such as rivers without running the risk of producing narrow, elongate cells that tend to produce numerical instabilities as it is often the case with MODFLOW.

Lake water level was specified as inputs before the model run and inflows to the lake were calculated with the groundwater model(s). Since results from the FEFLOW-based model were only available from 2010, data were projected back to start in 1997, i.e. using the data from 1 January 2010 for 1 January 1997.

Evaporation from the lake surface is an important lake water sink. The Lake Kepwari model was used to calculate the evaporation for a period of 13 years (1997-2009). The calculation was performed with the term algorithm of CE-QUAL-W2 (Cole and Buchak, 1995) with evaporation calculated for each iteration step. The step length can be from one hour to several seconds depending on numerical criteria. Evaporation depended on air and dew point and surface water temperature, and wind speed, which was calculated using a heat budget model. Daily results were saved for all model cells at the surface and aggregated to monthly average values for the whole lake over the total calculation time.

No evaporation calibration was made. All results were calculated with input metrological data and the internal parameters of CE-QUAL-W2. Good correspondence with measured evaporation values suggested that projections of evaporation rates into the future with metrological input data were possible allowing for the investigation of the abstraction effects on the water budget of the lakes.

\section{Results}

\subsection{New, rehabilitated lakes - Lake Kepwari}

\subsubsection{Model run without groundwater inflow}

The model was run without any groundwater inflow. The expected outcome would be a lake level below measured values that would indicate how the groundwater contributes to the volume change of the lake. The water level over time is shown in Figure 3(a) and shows similar patterns of rapid increase of water level or volume during flooding periods with water from River Collie and plateaus in between. At lower water levels the water level increased rapidly with increases in volume; increasing less and less at higher water levels with the same amount of volume added.

There were three distinct phases:

1. A pre-flooding phase before mid 1999 with only groundwater inflow, no Collie River water filling.

2. A flooding phase from mid 1999 to mid 2004 with several short periods of flooding with Collie River water. There was a small flooding event in mid 2005; however, the volume was about only one tenth of that of the other flooding periods. For simplicity, this flooding period is included in the next phase.

3. A post-flooding phase from mid 2004 onwards with, again, only groundwater inflow, and no significant diversions of the Collie River water anymore.

These phases can be clearly seen in Figure 3(a). In the pre-flood phase calculated water level and volume lag behind the measured values. This is due to the fact that there is no groundwater inflow in the model but the lake water level is low compared to the surrounding groundwater levels and a groundwater inflow is expected.

In the flooding phase the volume difference between calculated and measured values was similar until mid 2003. From mid 2003-2004 there was a sharp increase of calculated volumes compared to measured values. Groundwater hydraulics can explain this. The very fast increase in lake water levels during flooding reduced the near-lake groundwater gradient to essentially zero preventing any groundwater inflow. When lake water 
level increased even further, the gradient will likely be reversed and the lake flows into the subsurface. The model does not allow any outflow; hence the calculated lake volume is larger than the measured one.

In the after-flood phase the measured water level reached a quasi steady-state with only seasonal changes. The calculated water level slowly fell due to evaporation and no other source except precipitation, which was lower than evaporation. This suggests groundwater inflows must be generally higher than outflows.

\subsubsection{Inflow from MODFLOW-based groundwater model}

Groundwater inflows calculated by the MODFLOW-based model were added in the model (Figure 3(b)). The model greatly overestimated the increase of water in the lake if the groundwater inflow was added. This is probably because the groundwater model was designed for large scale investigations of the groundwater flow. The spatial discretisation of the groundwater model was too large to allow for detailed inflow volumes. Furthermore, Lake Kepwari was represented in the model as a static boundary condition, where the specified lake water level determines how much water flows into the lake. Consequently, only inflow and no outflow were calculated. While these are reasonable assumptions for investigations of large-scale groundwater flow conditions, the model results are not suitable as inputs for a detailed lake model.

In the pre-flooding phase the inflow provided by the groundwater model was larger than expected as at this stage the lake volume and therefore the contact area with the groundwater was significantly smaller than that of the full lake used in the groundwater model. Although Lake Kepwari received groundwater inflow during this phase, it would have to be much less than the flow calculated with the groundwater model.

a)
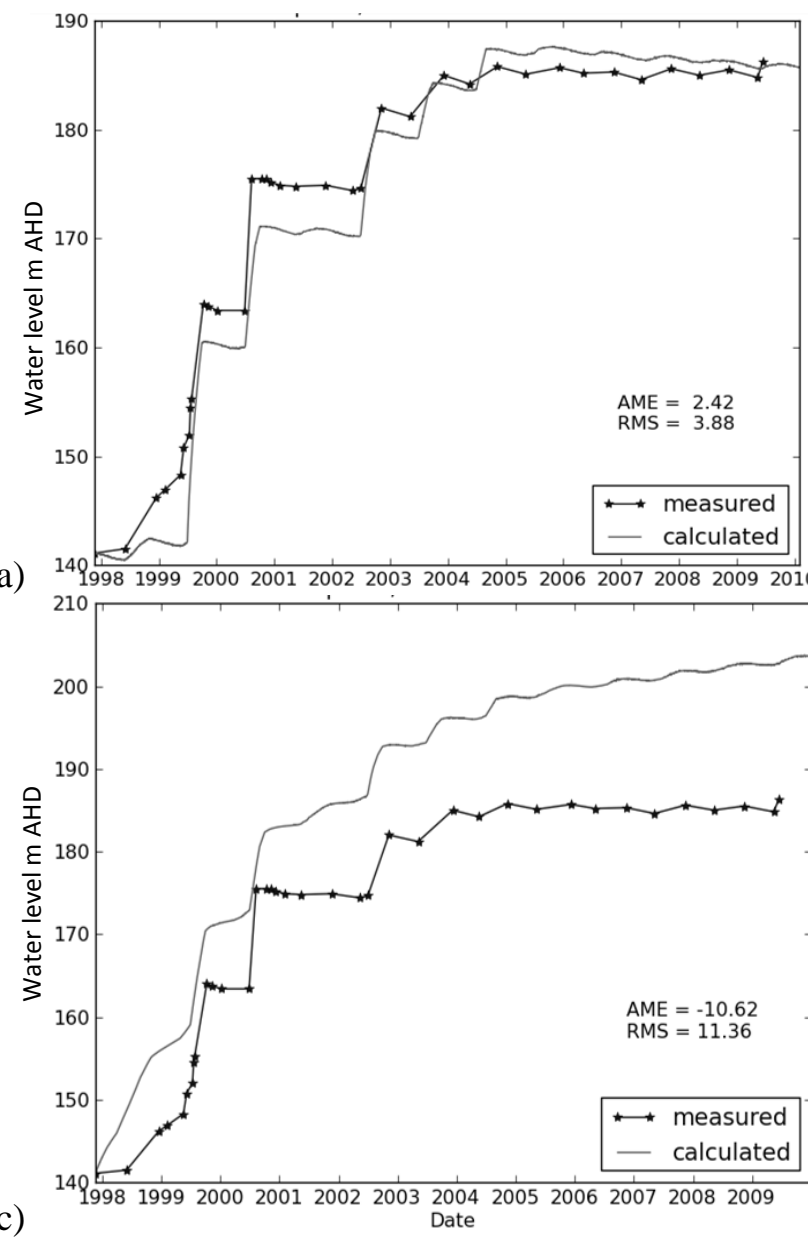

b)
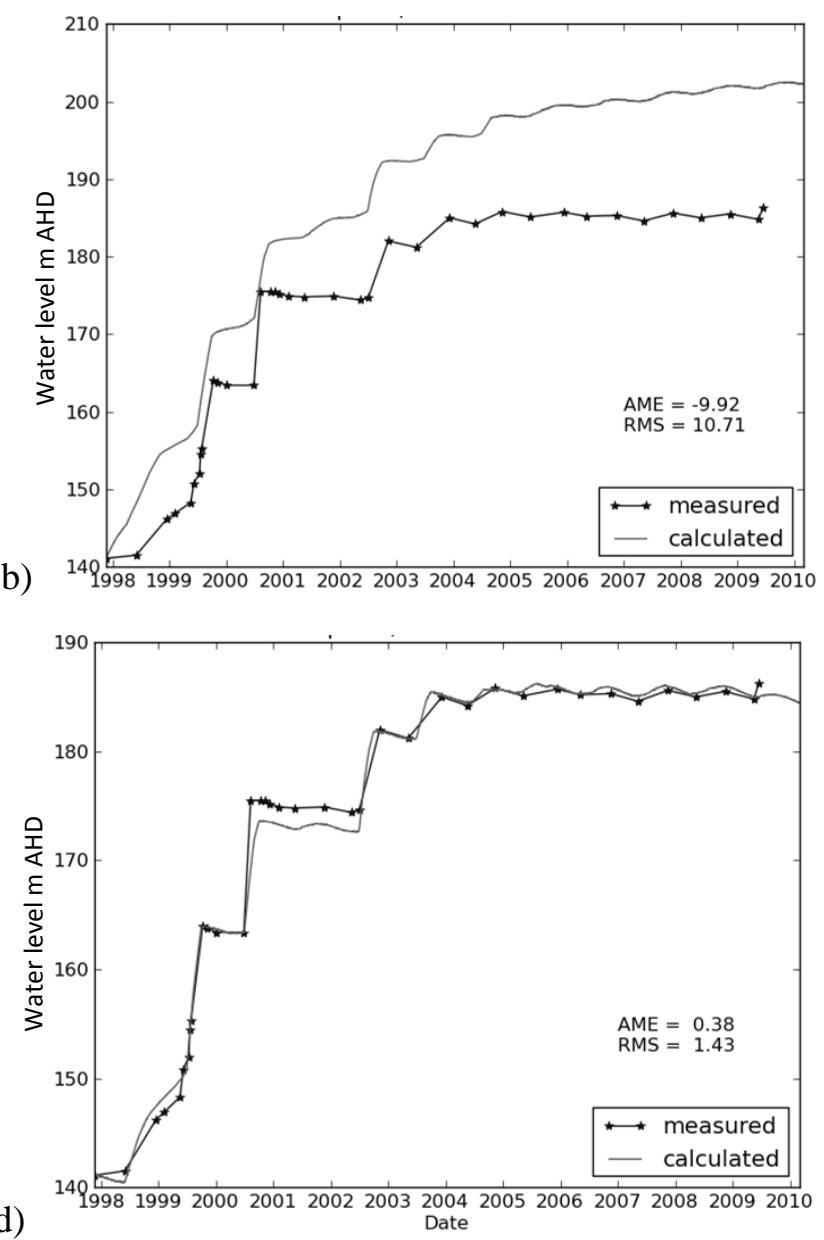

Figure 3 Comparison of measured and calculated water levels of Lake Kepwari over time a) without groundwater inflow, b) using inflows as calculated by the MODFLOW-based model and, c) using inflows as calculated by the FEFLOW-based model with current abstraction from groundwater, d) Comparison of measured and calculated water levels of Lake Kepwari for the likely, minimal, and doubled groundwater scenario 
During the first part of the flooding phase no groundwater inflow was expected as the groundwater model did not take into account flooding. In post-flooding phase the lake was expected to have groundwater outflows along with inflows. Since the groundwater model only provided inflows, the modelled lake volumes increased steadily to more than twice the measured values.

\subsubsection{Inflow from FEFLOW-based groundwater model with current abstraction}

The groundwater inflow from FEFLOW-based model with the current abstraction produced similar results as the MODFLOW-based model for the lake water level (Figure 3(c)). The results for the licensed abstraction are similar and therefore not shown here.

\subsubsection{Selection of groundwater scenarios for further calculations}

None of the available groundwater inflows could be used for further calculations because the groundwater models were designed for different purposes and therefore cannot provide useful values for this specific study. In order to generate suitable model outputs for lake water level modelling, the groundwater model would need several modifications including increasing its spatial discretisation in the vicinity of the lake so that more groundwater model cells border to the lake.

The flooding process of the lake needs to act as dynamic boundary condition to the groundwater model. The inflow from the Collie River needs to be considered as well as precipitation, evaporation and surface runoff. The best solution for this problem would be a coupled groundwater-lake model in which the lake water level is calculated by a lake model and provided to the groundwater model as a boundary condition. The groundwater model could calculate the groundwater inflows and outflows and provided them as a boundary condition for the lake model. The bilateral exchange would happen every time step in the order of one day to one month. Since such a model was not available, a reasonable groundwater inflow and outflow regime was deduced from the available data. This inflow was different for the different phases. In the pre-flooding phase groundwater inflow was assumed to be the only input source besides surface runoff. Therefore, its value can be estimated by solving the inverse problem and the groundwater inflow values were adjusted to yield the measured volume change in the lake.

During the first part of the flooding phase no groundwater inflow or groundwater outflow was assumed, supported by the calculation without groundwater inflow as shown in Figure 3(a). During the last part of the flooding phase and in the post-flooding phase both groundwater inflow and groundwater outflow were likely present. Calculated lake volume exceeded the measured volumes even without groundwater exchange and the lake water level steadily decreased (Figure 3(a)). Unfortunately, the contributions of inflow and outflow could not be uniquely determined as there is an unlimited combination of inflows and outflows that could result in the same lake water volume development.

The following groundwater inflow and outflow scenarios were based on deductions. Three different groundwater inflow/outflow scenarios were generated following the reasoning above using the same inflow and outflow amounts until July 2004. After this the amounts vary. Likely groundwater inflow/outflow used inflow amounts from the MODFLOW-based groundwater model from July 2004 onwards. The outflow was calculated to get a close agreement between measured and calculated water levels and volumes.

Minimal groundwater inflow/outflow minimised inflow from July 2004 onwards by reducing inflow volumes from the MODFLOW-based groundwater model by the outflows. This scenario yielded the smallest possible groundwater exchange while still preserving the seasonal groundwater flow variation calculated with the MODFLOW-based groundwater model.

Doubled groundwater inflow/outflow used twice the inflow amounts from the MODFLOW-based groundwater model from July 2004 onwards. The outflow was calculated from the close agreement between measured and calculated water levels and volumes (Figure 3(d)).

\subsection{Historic lakes - Lake Stockton}

The lake inflows calculated with the FEFFLOW-based groundwater model were applied as there was no data for the MODFLOW-based inflow. Again, the data was available from 2010 onwards. In order to be consistent with the approach for Lake Kepwari, data were projected back to 1997, using data from 1 January 
2010 as 1 January 1997. There was a very clear trend of a falling water level indicating the need for more inflow to the lake to maintain its current water level. Since no observation data for the lake water level were available, the current water table is shown as reference. The assumption was that the water table is approximately stable over time. Seasonal variations are not shown but are likely present as the model suggests. A compensation inflow rate was then determined and a constant value of $0.0012 \mathrm{~m}^{3} / \mathrm{s}$ produced a water table that varies around the current water table (Figure 4).

a)

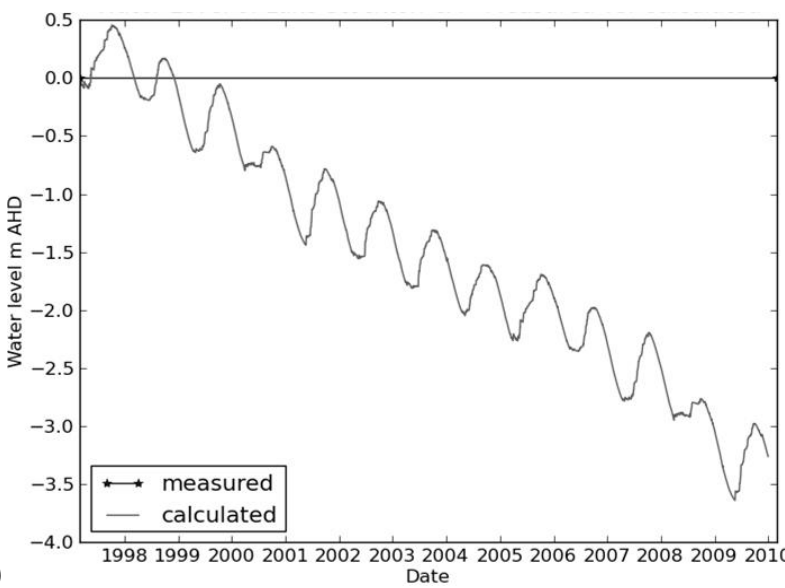

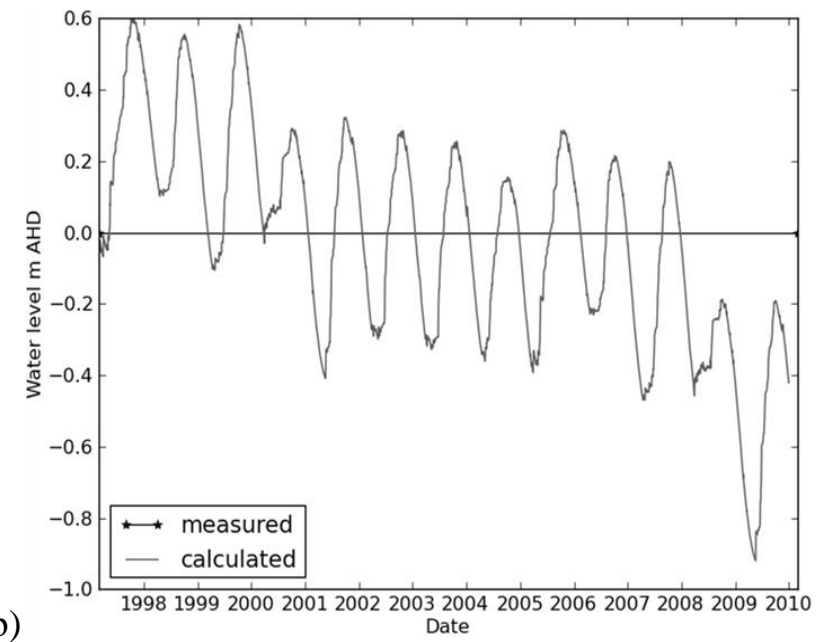

Figure 4 Water levels in Lake Stockton over time using the inflows as calculated by the FEFFLOWbased model with current abstraction from groundwater a) without and, b) compensation (April 2010 level at zero)

\subsection{New and un-rehabilitated lakes -Lake WO5C}

No groundwater inflow data was available for Lake WO5C so a calculation without inflows was made showing clearly that inflows were needed to reproduce the measured water levels over time (Figure 5(a)). A compensation inflow rate was also determined. Besides seasonal variations, there was a clear trend of declining inflow rates. Using this compensation flow, a reasonable agreement between measured and calculated water table levels could be achieved (Figure 5(b)).

a)

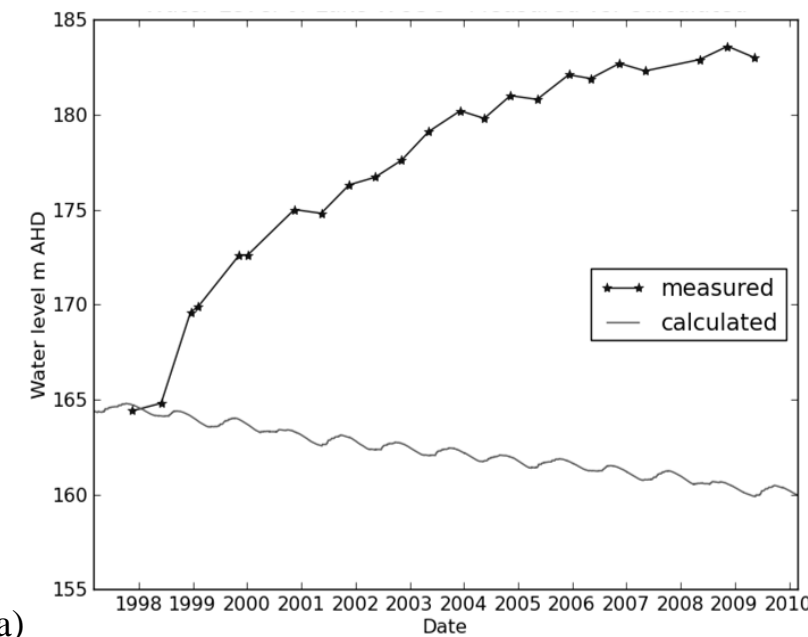

b)

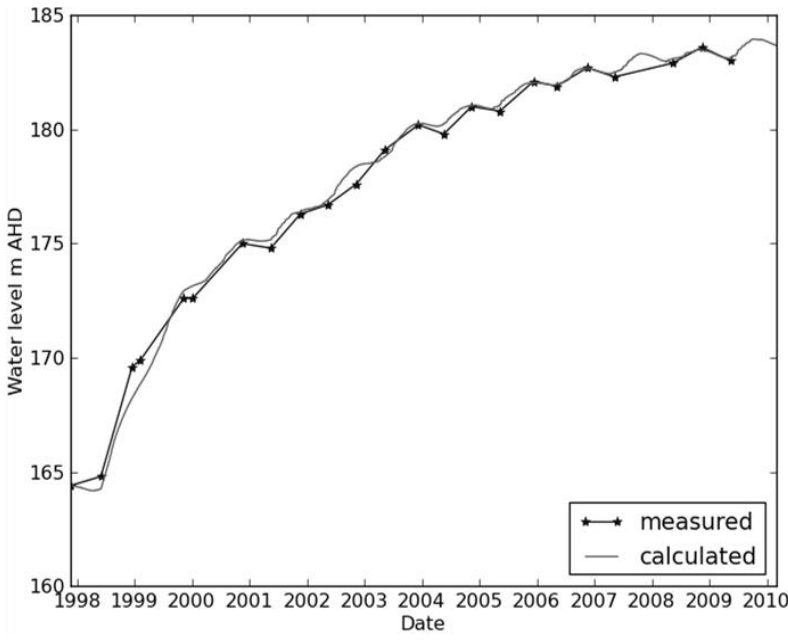

Figure 5 Comparison of measured and calculated water levels in Lake WO5C over time a) without compensation and, b) with compensation 


\section{Discussion and conclusions}

Model predictions should not be regarded as perfectly accurate due to the inherent uncertainties in input datasets and in understandings of fundamental groundwater and lake processes such as climatic interactions and groundwater flow characteristics. However, process-based models still allow us to integrate complex physical processes that interact across multiple time and space scales. As our study shows, they also can provide quantitative estimates of outcomes under different environmental and operational scenarios.

Pit lake modelling for Collie was clearly limited by available data both from the pit lakes and particularly from groundwater model results. The groundwater inflow calculated by the groundwater models deviated considerably from inflows suggested by this study. This is because the groundwater models are large scale models where the lakes are small features and not the main concern of the existing groundwater modelling studies. Furthermore, in the groundwater models, lakes are represented as general head boundary conditions. This means that lake water levels have to be specified as input values. Unfortunately, these lake water levels have to be computed using the groundwater exchange as a source or sink.

Incorporation of new lake boundary conditions in the groundwater model based on the results of this study could improve the results considerably. The preferred approach would be a coupled lake-groundwater model. For this, a detailed groundwater model with fine discretisation in the vicinity of the lake will get its external boundary conditions from the large scale model. Coupling this detailed groundwater model to the lake model would provide a continuous feedback loop between lake and groundwater resulting in detailed groundwater exchange rates with high spatial and temporal resolution. This would allow investigation of climate change impacts on the lake-groundwater system and would provide a good basis for lake water quality modelling.

Bathymetry data were also very important to calculate accurate lake volumes and for reliable representation of spatial distribution of shallow and deep areas of a lake. Bathymetry data for Lake Stockton was obtained during this study but can be considered as estimates and need further refinement to improve the model representation of the real lake bathymetry. Bathymetry data should also be collected for other pit lakes, particularly historic lakes, so that these can be modelled.

The influence of groundwater on lake water quality can only be evaluated based on the regional models groundwater exchange scenarios; with inherent uncertainties at the pit lake scale. However, the changes planned for groundwater abstraction regimes are relatively small, and of far less consequence to the pit lakes, than the current uncertainties involved with modelled groundwater exchange. Therefore, based on available data, no final conclusions on the influence of abstraction regime changes on lake water budgets could be drawn.

Nevertheless, our modelling scenarios still provide a quantitative basis for a better understanding of important hydrological processes for the different lake types. Even though we could not provide full solutions for the groundwater exchange processes, we could exclude less likely, and point to more, likely, pit lake water level scenarios. We could also identify our major limiting data set; groundwater processes, for targeting in further studies. Further modelling investigations into water quality processes in addition to groundwater exchange are planned as these processes may be important in determining long-term pit lake water level and water quality controls. Modelling results strongly support the need for more site-specific investigations and pit lake-oriented groundwater modelling to accurately predict long-term pit lake levels of the District and also to improve regional groundwater models.

This example illustrates pit lake modelling with low data availability are still useful in better understanding long term pit lake risks at closure.

\section{Acknowledgements}

Thanks to Dr Digby Short and Premier Coal for pit void shell data and site access for bathymetric surveying. This project was part funded by the Australian Government's "Water for the Future initiative".

\section{References}

Bell, L.C. (2001) Establishment of native ecosystems after mining - Australian experience across diverse biogeographic zones, Ecological Engineering, Vol. 17, pp. 179-186. 
Castendyk, D.N. and Webster-Brown, J.G. (2007) Sensitivity analyses in pit lake prediction, Martha Mine, New Zealand 1: Relationship between turnover and input water density, Chemical Geology, Vol. 244(1-2), pp. 42-55.

Cole, T.M. and Buchak, E.M. (1995), CE-QUAL-W2: A two-dimensional, laterally averaged, hydrodynamic and water quality model, 2.0, US Army Corps of Engineers, Waterways Experiment Station, USA.

Craven, E. (2003) Acid Production in the Overburden of Lake WO5B, Collie. Environmental Engineering Project 640.406, thesis, Centre for Water Research, University of Western Australia, Australia, Perth, November 2003.

Doupé, R.G. and Lymbery, A.J. (2005) Environmental risks associated with beneficial end uses of mine lakes in southwestern Australia, Mine Water and the Environment, Vol. 24(3), pp. 134-138.

Eary, L.E. (1999) Geochemical and equilibrium trends in mine pit lakes, Applied Geochemistry, Vol. 14(8), pp. 963-987.

Farrell, T. (1998) Major decommissioning issues for the Australian mining industry, Proceedings of the Workshop on Environmental Issues in the Decommissioning of Mine Sites, Australian Centre for Mining Environmental Research (ACMER), Kenmore, Australia, pp. 11-15.

Hamblin, P.F., Stevens, C.L. and Lawrence, G.A. (1999) Simulation of Vertical Transport in Mining Pit Lake, Journal of Hydraulic Engineering, Vol. 125(10), pp. 1029-1038.

Huber, A., Ivey, G.N., Wake, G. and Oldham, C.E. (2008) Near-surface wind-induced mixing in a mine lake, Journal of Hydraulic Engineering, Vol. 134(10), pp. 1464-1472.

Jin, Q. and Bethke, C.M. (2005) Predicting the rate of microbial respiration in geochemical environments, Geochimica et Cosmochimica Acta, Vol. 69(5), pp. 1133-1143.

Johnson, S.L. and Wright, A.H. (2003) Mine void water resource issues in Western Australia, Hydrogeological Record Series, Report HG 9, by Water and Rivers Commission, Perth, Australia, 93 p.

Kalin, M., Cao, Y., Smith, M. and Olaveson, M.M. (2001) Development of the phytoplankton community in a pit-lake in relation to water quality changes, Water Research, Vol. 35(13), pp. 3215-3225.

Kumar, R.N., McCullough, C.D. and Lund, M.A. (2009) Water resources in Australian mine pit lakes, Mining Technology, Vol. 118(3/4), pp. 205-211.

Lund, M.A. and McCullough, C.D. (2008) Limnology and ecology of low sulphate, poorly-buffered, acidic coal pit lakes in Collie, Western Australia, Proceedings of the 10th International Mine Water Association (IMWA) Congress, Karlovy Vary, Czech Republic, N. Rapantova, Z. Hrkal (eds), pp. 591-594.

McCullough, C.D. and Lund, M.A. (2006) Opportunities for sustainable mining pit lakes in Australia, Mine Water and the Environment, Vol. 25(4), pp. 220-226.

McCullough, C.D. and Lund, M.A. (2010) Mine Voids Management Strategy (IV): Conceptual Models of Collie Basin Pit Lakes, Department of Water Project Report by MiWER/Centre for Ecosystem Management Report 2010-12, Edith Cowan University, Perth, Australia. Unpublished report to Department of Water.

McCullough, C.D., Hunt, D. and Evans, L.H. (2009) Sustainable development of open pit mines: creating beneficial end uses for pit lakes, Mine Pit Lakes: Characteristics, Predictive Modeling, and Sustainability, D. Castendyk, T. Eary, B. Park (eds), Society for Mining Engineering (SME), Kentucky, USA, pp. 249-268,

Miller, G.E., Lyons, W.B. and Davis, A. (1996) Understanding the water quality of pit lakes, Environmental Science and Technology, Vol. 30(3), pp. 118A-123A.

Müller, M. (2004) Modellierung von Stofftransport und Reaktionen mit einem neuent $\neg$ wickelten, gekoppelten Grundund Oberflächenwassermodell am Beispiel eines Tagebaurestsees, thesis, Dresden.

Müller, M. (2011) The PITMOD website, viewed 1 May 2011, http://www.pitmod.com.

Müller, M. and Werner, F. (2004) Groundwater-Lake-Interactions at Lake Bärwalde and its Implications on Predictions of Lake Water Quality, Proceedings of International Conference on Finite Element Models, MODFLOW, and More: Solving Groundwater Problems, K. Kovar, Z. Hrkal \& J. Bruthans (eds), 13-16 September 2004, Karlovy Vary, Czech Republic, pp. 249-252.

Niccoli, W.L. (2009) Predicting Groundwater Inputs to Pit lakes (Chapter 8), Mine pi lakes: characteristics, predictive modeling, and sustainability, D.N. Castendyk and L.E. Eary (eds) Society for Mining, Metallurgy \& Exploration (SME), Littleton, Colorado, USA, pp. 91-99.

Parkhurst, D.L. and Appelo, C.A.J. (1999) User's guide to PHREEQC (Version 2) - A computer program for speciation, batch-reaction, one-dimensional transport, and inverse geochemical calculations, Water-Resources Investigations Report 99-4259, by U.S. Geological Survey, 310 p.

Salmon, S.U., Oldham, C. and Ivey, G.N. (2008) Assessing internal and external controls on lake water quality: limitations on organic carbon-driven alkalinity generation in acidic pit lakes, Water Resources Research 44(W10414).

Sappal, K., Zhu, Z.R., Rathur, Q. and Hodgkin, T. (2000) Subsurface geology, hydrogeological and geochemical analysis of the Ewington Open Cut No 2 lake area, Collie Basin, Final void water quality enhancement: Stage III, ACARP Project Number C8031 report, Perth, pp. 11-68.

Varma, S. (2002) Hydrogeology and groundwater resources of the Collie Basin, Western Australia, Hydrogeological Record Series HG 5, by Water and Rivers Commission, Perth. 80 p. 
Waterhouse, J.A. and Davidge, S. (1999) The evolution of the water body in the final void of the Mount Goldsworthy Mine, Proceedings Water 99 Joint Congress, 6-8 July 1999, Brisbane, Australia, pp. 895-900.

Werner, F., Eulitz, K., Graupner, B. and Müller, M. (2008) Pit Lake Bärwalde Revisited: Comparing Predictions to Reality, Proceedings of the 10th International Mine Water Association (IMWA) Congress, Karlovy Vary, Czech Republic, 4 p.

Zhang, Q., Varma, S., Bradley, J. and Schaeffer, J. (2007) Groundwater model of the Collie Basin, Western Australia, Hydrogeological Record Series, Report HG 15, Water and Rivers Commission, Perth, Australia, 106 p. 
